\title{
Article
}

\section{How the emergency department four- hour target affects clinical outcomes for patients diagnosed with a personality disorder}

\author{
Haslam, Michael \\ Available at http://clok.uclan.ac.uk/33563/ \\ Haslam, Michael ORCID: 0000-0002-9076-1481 (2019) How the emergency \\ department four-hour target affects clinical outcomes for patients diagnosed \\ with a personality disorder. Emergency Nurse, 27 (4). pp. 20-24. ISSN 1354- \\ 5752
}

It is advisable to refer to the publisher's version if you intend to cite from the work. http://dx.doi.org/10.7748/en.2019.e1930

For more information about UCLan's research in this area go to http://www.uclan.ac.uk/researchgroups/ and search for <name of research Group>.

For information about Research generally at UCLan please go to http://www.uclan.ac.uk/research/

All outputs in CLoK are protected by Intellectual Property Rights law, including Copyright law. Copyright, IPR and Moral Rights for the works on this site are retained by the individual authors and/or other copyright owners. Terms and conditions for use of this material are defined in the policies page.

\section{CLoK}

Central Lancashire online Knowledge www.clok.uclan.ac.uk

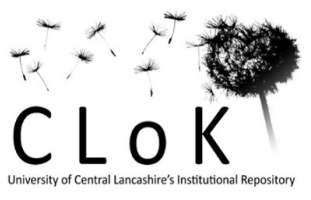


How the Emergency Department's target affects clinical outcomes for patients diagnosed with a personality disorder

\section{Abstract}

The Emergency Department (ED) may already be an invalidating environment for those patients diagnosed with a personality disorder, with negative attitudes from staff perpetuating feelings of dismissal and rejection. Despite, however, personality disorder being more prevalent across health services including EDs, there is a lack of literature considering how achieving the target may take a priority over clinical need, leading to adverse outcomes for those patients diagnosed with a personality disorder.

Expanding on Hardern's application of the concept of Destructive Goal Pursuit to the four-hour target, existing literature is used to illustrate how pressures to meet the four-hour target may a lead to distortions of clinical priorities and to adverse clinical outcomes for this patient group.

This paper challenges the concept of the target as being realistic and helpful to those patients specifically diagnosed with a personality disorder. Recommendations for practice include the use of short-stay units, where patients may be treated outside of the target wait time and the introduction of mental health triage in ED to improve the delivery of psychosocial assessments.

\section{Background}

The four-hour target has transformed the way in which emergency care is delivered in the UK, with efforts being made to eliminate delays (DH, 2001; Mortimore \& Cooper, 2007). Conceived as a simple measure of quality (Campbell, et al. 2017), the target has improved the experience of the patient journey, increasing patient satisfaction through reduced wait times and investigation delays (Mortimore \& Cooper, 2007). However, as staff come under increasing pressures to meet the target, its negative influence on workload and the quality of care delivered has been a contributory factor in the fall of staff morale (Mortimore \& Cooper, 2007). Also, there does not appear to have been any empirical justification specifically for the target of four hours (Hoyle \& Grant, 2015).

Complexities of the illness and the need to communicate with families and external agencies mean that the four-hour target may not always be attainable for those with mental ill health (Bastiampillai, et al. 
2012; Coates, et al. 2018). Longer stays may occur due to the additional complexities of comorbid illness, additional psychosocial stressors, the need for medical clearance and for some patients to be stabilised in times of crisis (Smith, et al. 2016). For patients diagnosed with a personality disorder, a variable provision of local services (NIMHE, 2003) means that they often seek help at the 'margins' of healthcare, such as EDs. Prevalence of personality disorder is higher in clinical settings compared to the general population possibly due to an increase in patient health-seeking behaviours (Tyrer, et al. 2015). Despite this, staff feel unskilled and unprepared to work with this patient group (NICE, 2009; Karman, et al. 2014).

For the patient in crisis, ED may already be an invalidating environment. Negative staff attitudes, particularly towards those who attend with repeat self-harming behaviours, have an adverse effect on the quality of care delivered (Hadfield, et al. 2009; Saunders et al. 2011; Conlon \& O'Tuathail, 2012; Shaikh, et al. 2017). When managing crises, it is a recommendation that time be offered to patients and that a supportive and collaborative relationship is developed (NCCMH, 2009; McMain, et al. 2015). Crisis interventions are important in addressing any acute symptoms of distress and in calming the patient (Shaikh, et al. 2017). Pressures to meet the target, however, reduce opportunities to develop a therapeutic alliance, increasing the risk of invalidating responses. For those seeking support in crisis this has the potential to perpetuate feelings of dismissal and rejection.

\section{Distortions of clinical priorities}

Hardern's (2012) application of the concept of destructive goal pursuit to the target is useful; highlighting how increasing pressures to manage patients within a limited time-period has the potential to lead to a distortion of clinical priorities (Figure 1), affecting both communication and patient satisfaction (Mortimore \& Cooper, 2007). Goal-setting can become dysfunctional when the goal is narrowly-defined, autonomy is decreased and when there is both a complex system in place and additional pressures to achieve the goal (Kayes, 2006). Efforts to ensure that the target is not breached may lead to an increase in clinical risk-taking and unethical behaviours. For those diagnosed with a personality disorder, patient safety may be compromised through avoidance, poor communication, a lack of thorough assessment, hasty discharges and avoidable inpatient admissions. 
Avoidance

Rather than improving outcomes, the target may result in avoidance behaviours that have the potential to compromise patient safety. In the pursuit of achieving the four-hour target, those cases which are deemed to be less complex might be seen in a timelier manner, over those who might have been seen earlier before the introduction of the target (Hoyle \& Grant, 2015). In this way therefore, the target favours less-complex patients, whose problems may be resolved sooner (Campbell, et al. 2017).

\section{Poor communication}

An empathic, patient-centred and collaborative approach (NICE, 2009; Betz \& Boudreaux, 2015) should be used when communicating with patients diagnosed with a personality disorder. Using a direct and open style enhances communication thus raising the quality of assessment. Constraints, however, placed on ED clinicians due to the target, restrict both time and communication with the patient, affecting both on the quality of care and patient safety (Mortimore \& Cooper, 2007). Poor communication may lead to non-concordance with treatment options, further compounding negative responses from clinicians. These responses in turn may lead to adverse outcomes such as avoidable inpatient admissions, inadequate assessment of risk and the avoidable use of medication and restraint (Shaikh, et al. 2017) contrary to the national guidance (NICE, 2009).

A lack of a thorough assessment

For those patients who have self-harmed, the importance of a full psychosocial assessment is one that is repeated throughout the literature. Psychosocial assessments reduce the risk of further self-harm (Mullins, et al. 2010; UI Haq, et al. 2010; Steeg, et al. 2017) through the identification of specific needs and ensuring appropriate treatment and follow-up for individuals (Parsonage, et al. 2012). Patients attending ED having self-harmed however may not be offered a full psychosocial assessment routinely, contrary to guidance (Mullins, et al. 2010); a reflection of the time pressures faced by clinicians in ED (Ul Haq, et al. 2010) although this may also be attributed to a difference between the patient and clinician's perceptions of the patient's problems and intent (Wise-Harris, et al. 2017). Pressures to rapidly discharge a patient to avoid breaching the target and before the correct information is available may lead to a failure to correctly estimate the individual's risk, compromising patient safety (NCCMH, 2009). 
A hasty discharge

For those patients in crisis, a discrepancy between their own views and those of the clinicians assessing them, as to what constitutes an appropriate visit, may lead to feelings for the patient that they were 'dismissed' by ED staff (Wise-Harris, et al. 2017). Discharges may be construed as poor treatment if the patient does not feel that they received an adequate assessment and treatment (Welch, 2010). Endings and transitions must therefore be managed carefully (NICE, 2009) and for those patients who perceive that they have been discharged too rapidly, there is an increased risk for the patient of further self-harm and escalating behaviours (Wise-Harris, et al. 2017).

\section{Avoidable inpatient admissions}

An alternative to a hasty discharge may be an avoidable inpatient admission, either to a medical or psychiatric inpatient facility. Combined with the pressures of the four-hour target, difficulties obtaining previous notes and collateral information increase the potential for avoidable inpatient admissions (Hunter, et al. 2015). Although it is difficult from data studies to establish the suitability of each admission, difficulties encountered in ensuring a safe and therapeutic discharge through care packages mean that the potential for avoidable admissions are increased, shifting these responsibilities to inpatient teams outside of the target (Gorski, et al. 2009; Pope, et al. 2017). This course of action has a significant financial effect for the Trusts involved as well as implications for patients whom might be relatively more unwell and whose admissions would be delayed further due to an increased strain on the availability of inpatient beds (Hardern, 2012).

For the patient diagnosed with a personality disorder, the decision to admit to hospital is complex. Admissions, particularly to mental health inpatient facilities as part of routine care, may have therapeutic benefits, ensuring a safe setting where patients might recover away from relational struggles and to enable the completion of a psychosocial assessment (NICE, 2013). Routine admissions, however, may reduce the likelihood of the person developing skills to manage crises for themselves (NICE, 2009), and there are conflicting findings regarding the effects of an inpatient admission on the risk of further self-harm (Hjorthoj, et al. 2014; Carroll, et al. 2016; Steeg, et al. 2017). Whilst an admission may be helpful overnight if the person is distressed or has an unsafe home environment (NICE, 2013) guidance 
recommends that the patient remains actively involved in finding solutions to their own problems when in crisis and the exploration of alternative solutions (NICE, 2009).

Such admissions may be avoidable if clinicians have extra time to complete their assessment of the patient and to develop a therapeutic alliance (Pope, et al. 2017). Instead the target places an emphasis on clinical triage and 'gatekeeping' (Gorski, et al. 2016) rather than actual treatment, impinging on the clinician's abilities to comprehensively manage the patient within ED (Pope, et al. 2017). Also, despite the decision already being made to admit a patient early, those selected for admission, are not always likely to experience a shorter overall patient journey (Swancutt, et al. 2017), irrespective of the availability of beds (Bastiampillai, et al. 2012).

Implications and recommendations for practice Further research is needed to establish the effects of the four-hour target on clinical outcomes for this patient group and, where there is a risk of distorted responses from staff due to the target, measures might be taken to minimize this risk. Policy-makers may consider allowing Trusts to develop their own resolutions, granting senior clinicians a greater autonomy and the authority to breach the target for atrisk patient groups if required (Hoyle \& Grant, 2015; Pope, et al. 2017).

Shorter-term and more realistic solutions might include a wider use of specialist short-stay units and discharge lounges where patients in crisis might be assessed and treated outside of the scope of the target. Discharge lounges for those patients who are medically cleared, would ensure a rapid return to the community, reducing the reliance on inpatient beds (Mortimore \& Cooper, 2007) and with a focus on a detailed assessment and delivering short-term crisis interventions. A potential challenge, however, is in preventing those patients presenting to ED with relatively minor ailments and who have not yet breached the target, being diverted to areas with less monitoring and staff; where ultimately, they may wait longer (Hoyle \& Grant, 2015; Campbell, et al. 2017).

Those patients who receive a psychosocial assessment, compared to those who receive routine care alone, report better experiences and have a reduced risk of repeat hospital attendance for self-harm (Steeg, et al. 2017), contrary to the belief that an increase in satisfaction also leads to increased 
attendances (Wise-Harris, et al. 2017). A lack of coherence and consensus, however, exists between guidance documents with regards to the process of assessment whilst a variability in the provision of hospital mental health liaison services may also account for the current differences in assessment within practice when working with patients who have self-harmed (HSIB, 2018).

Recommendations, therefore, include the introduction of mental health triage, both decreasing wait times and increasing awareness for staff to the needs of patients diagnosed with a personality disorder; promoting more favourable outcomes (Mullins, et al. 2010). Present guidance recommends that ED staff must be competent in identifying mental health problems in those patients attending ED (NHS England, 2017). However, the triage process completed by ED nurses alone, may lack a robust structure when assessing a patient's mental state, leading to inconsistencies (HSIB, 2018). A solution, therefore, would be to integrate the hospital mental health liaison team into the triage process regardless of the reasons for patient attendance. Mental health triage is most effective where the mental health liaison team have a permanent and integrated presence in ED, are able to conduct parallel assessments (HSIB, 2018) and to proactively advise on management strategies of those patients diagnosed with a personality disorder, who attend frequently.

Where it is not possible due to variabilities in the provision of this service, to integrate the hospital mental health liaison team fully into ED, appropriate training and support delivered to staff in ED, via mental health liaison services are shown to improve the quality of triage (NHS England, 2017) and psychosocial assessments for patients in crisis (UI Haq, et al. 2010). Those staff trained in the delivery of a risk assessment at triage are better at assessing suicide intent and routinely record the patient's capacity and willingness to remain in ED where the patient might be at risk of absconding (Mullins, et al. 2010). Such training sensitizes staff both to the factors that influence those who attended frequently (Karman, et al. 2014); reducing negative attitudes, whilst also promoting the importance of a referral to timely and suitable aftercare (Wise-Harris, et al. 2017).

Limitations of this paper

A weakness is that this paper does not consider the effects of ED census; an issue that may also be ascribed to the same distortions in clinical priorities as those attributed to the four-hour target. Increases 
in ED census intensifies pressures on staff and resources increasing the likelihood of errors and the avoidance of more complex tasks (Gorski, et al. 2016). This topic is of interest due to the potential effect of increased ED census on the attainment of four-hour target.

\section{Conclusion}

Factors beyond patient symptomology and severity of illness have the potential to have an effect on clinical outcomes in ED. Work pressures and time constraints in ED caused by the four-hour target have the potential to lead to a distortion of clinical priorities, promoting unsafe care and excessive risk-taking by clinicians for some patient groups. The application of the model of destructive goal pursuit to the target is useful, highlighting how an increase in clinical risk-taking to meet the target has the potential to affect communication, patient satisfaction and to compromise patient safety. In the absence of any literature that directly considers the effect of the four-hour target on outcomes for those patients specifically diagnosed with a personality disorder, this paper uses existing literature to argue that this patient group is particularly vulnerable to being adversely affected by pressures to meet the target. It is concluded that for those patients diagnosed with a personality disorder, the four-hour target may not be realistic and attainable and that the perception of the target as being beneficial for all patients is challenged.

\section{References}

Bastiampillai, T., Schrader, G., Dhillon, R., Strobel, J. \& Bidargaddi, N. (2012) Impact of a Psychiatric unit's daily discharge rates on emergency department flow. Australasian Psychiatry, 20, 117120

Betz, M. E. \& Boudreaux (2015) Managing suicidal patients in the emergency Department. Annals of Emergency Medicine, 67, 276-282.

Campbell, P., Boyle, A. \& Higginson, I. (2017) Head to head: Should we scrap the target of a maximum four hour wait in emergency departments? British Medical Journal, 359

Carroll, R., Corcoran, P., Griffin., E., Perry, I., Arensman, E., Gunnell, D. \& Metclafe, C. (2016) Variation between hospitals in inpatient admission practices for self-harm patients and its impact on repeat presentation. Social psychiatry, 51, 1485-1493 
Coates, D.. David, M., Roberts, B. \& Duerden (2018) An examination of the profile and journey of patients with mental illness in the emergency department. International Emergency Nursing.

Conlon, M. \& O'Tuathail, C. (2012) Measuring emergency department nurses' attitudes towards deliberate self-harm using the Self-Harm Antipathy Scale. International Emergency Nursing, $20,3-13$

Department of Health (2001) Reforming Emergency Care. DH. London.

Gorski, J. K., Batt, R. J., Otles, E., Shah, M.N., Hamedani, A. G. \& Patterson, B. W. (2016) The impact of Emergency Department Census on the Decision to admit. Academic Emergency Medicine, 24, 13-21

Hadfield, J., Brown, D., Pembroke., L. \& Hayward, M. (2009) Analysis of Accident and Emergency Doctors' responses to treating people who self-harm. Qualitative health research, 19, 755765.

Harden, R. D. (2012) The 4-h target: an example of destructive goal pursuit. Journal of Emergency Medicine, 29, 219-221

Healthcare Safety Investigation branch (2018) Investigation into the provision of mental health care to patients presenting at the emergency department. HSIB.

Hjorthoj, C. R., Madsen, T., Agerbo, E. \& Nordentoft, M. (2014) Risk of suicide according to level of psychiatric treatment: a nationwide nested case-control study. Social psychiatry and psychiatric Epidemology. 49(9), 1357-1365

Hoyle, L. \& Grant, A. (2015) Treatment targets in emergency departments: nurses' views of how they affect clinical practice. Journal of Clinical Nursing, 24

Hunter, A. E., Spatz, E.S., Bernstein, S.L. \& Rosenthal, M. S. (2015) Factors influencing hospital admission of non-critically ill patients presenting to the emergency department: A crosssectional study. Journal of General International Medicine, 31(1), 37-44 
Karman, P., Kool, N., Poslawsky, I. E. \& Van Meijel, B. (2014) Nurses' attitudes towards self-harm: a literature review. Journal of Psychiatric and Mental Health Nursing, 22, 65-75

Kayes, C. D. (2006) Destructive goal pursuit: the Mount Everest disaster. Basingstoke, UK: Palgrave Macmillan

McMain, S. F., Boritz, T. Z. \& Leybman, M. J. (2015) Common strategies for cultivating a positive therapy relationship in the treatment of borderline personality disorder. Journal of Psychotherapy Integration, 25, 20-29.

Mortimore, A. \& Cooper, S. (2007) The "4-hour target": Emergency nurse's views. Emergency Medical Journal online, 402-404.

Mullins, D., MacHale, S. \& Cotter, D. (2010) Compliance with NICE guidelines in the management of self-harm. The Psychiatrist, 385-389.

National Collaborating Centre for Mental Health (2009) Borderline Personality Disorder. The NICE guideline on treatment and management. Commissioned by the National Institute for Health and Clinical Excellence and published by the British Psychological Society. London.

NHS England (2016) Achieving Better Access to 24/7 Urgent and Emergency Mental Health Care Part 2: Implementing the evidence-based treatment pathway for urgent and emergency liaison mental health services for adults and older adults.

National Institute for Health and Care Excellence (NICE) (2013) Self-harm: Quality Standard. NICE National Institute for Mental Health in England (NIMHE) (2003) Breaking the cycle of rejection: The Personality disorders capabilities framework. $\mathrm{NIMH}(\mathrm{E})$. Leeds.

Parsonage, M., Fossey, M. \& Tutty, C. (2012) Liaison Psychiatry in the Modern NHS. Centre for Mental Health, London.

Pope, I., Burn, H., Ismail, S. A., Harris, T. \& McCoy, D (2017) A qualitative study exploring the factors influencing admission to hospital from the emergency department. British Medical Journal Open, $7,1-8$

Saunders, K., Hawton, K. \& Fortune S. (2011) Attitudes and knowledge of clinical staff regarding people who self-harm; systematic review. Journal of Affective Disorders, 139, 205-216.

Shaikh, U., Qamar, I., Jafry, F., Hassan, M., Shagufta, S., Odhejo, Y. I. \& Ahmed, S. (2017) Patients with Borderline Personality Disorder in Emergency Departments. Frontiers in Psychiatry, 8, 112 
Smith, J. L., De Nadai, A. S., Storch, E. A., Langland-Orban, B., Pracht, E. \& Petrilla, J. (2016) Correlates of Length of Stay and Boarding in Florida Emergency Departments for Patients with Psychiatric Diagnoses. Psychiatric services, 67, 1169-1174

Steeg, S., Emsley, R., Carr, M., Cooper, J. \& Kapur, N. (2017) Routine hospital management of selfharm and risk of further self-harm: propensity score analysis using record-based cohort data. Psychological medicine, 1-12

Swancutt, D., Joel-Edgar, S., Allen, M., Thomas, D., Brant, H., Benger, J., Bying, R. \& Pinkney, J. (2017) Not all waits are equal: an exploratory investigation of emergency care patient pathways. BMC health services research, 17, 1-10.

Tyrer P, Reed G, Crawford M. (2015) Classification, assessment, prevalence, and effect of personality disorder. Lancet, 385, 717-726

UI Haq, S. U., Subramanyam, D. \& Agius, M. (2010) Assessment of self-harm in an accident and emergency service - the development of a proforma to assess suicide intent and mental state in those presenting to the emergency department with self-harm. Psychiatra Danunubina, 22, 26-32.

Welch, S. J. (2010) Twenty Years of patient satisfaction research applied to the emergency department: A qualitative review. American Journal of Medical Quality, 25, 64-72

Wise-Harris, D., Pauly, D., Kahan, D., Tan de Bibiana, J., Hwang, S. W. \& Stergiopoulos, V. (2016) "Hospital was the Only Option": Experiences of Frequent Emergency Department Users in Mental Health. Adm Policy Mental Health, 44, 405-412. 